\title{
Analysis of Dual Stator PM Brushless DC Motor
}

\author{
Ankita Dwivedi, R. K. Srivastava \\ Department of Electrical Engineering, IT-BHU Varanasi
}

\begin{abstract}
In this paper the analysis of dual stator permanent magnet BLDC (PMBLDC) motor has been reported. The proposed dual stator PMBLDC motor consists of two separate concentric stators having different number of slots with a common rotor on the same shaft. Two stator stampings of different radii are used for design of stators. The rotor is a hollow cylindrical rotor in the space between two stators. The analysis of the designed dual stator PMBLDC motor has been done. In dual stator machine, the total output torque corresponds to the algebraic sum of two independent torques.
\end{abstract}

Keywords: Dual stator motor, Permanent magnet BLDC (PMBLDC) motor, inner stator and outer stator.

\section{INTRODUCTION}

Dual stator topology has been widely used in motors for different applications where power segmentation and reliability are main concern. Dual stator configurations are already being used in induction, synchronous motors for applications like wind-mill generators, aircrafts, etc. In these dual stator machines, there are two stator windings which share the same magnetic and mechanical structures. These machines are typically used in high power applications. The stators may consist of two identical windings with or without phase shift. The two windings may have different number of poles, number of phases and ratings. In dual stator machine, the output torque corresponds to the algebraic sum of two independent torques. By having two independent torque components the low frequency operation, including standstill maneuvering can be improved [3].

PM brushless motor drives are successfully implemented in different electric propulsion systems. To improve the torque density, two air-gaps are combined in a motor to deliver the output torque and then the electromagnetic torque is produced by the separate currents of both stators. Based on this concept, the doublestator PM motor drive is introduced. It combines the double-stator structure of the PM brushless motor so as to provide high starting torque and good controllability for EV propulsion. Because of its unique configuration the motor can offer advantages of high torque density and good controllability [5].

Dual stator machines of various types are being recently considered for various motoring and generating applications. From the point of view of stator winding, dual stator machines have been categorized as "split-wound" and "self-cascaded". The winding of split-wound dual machine was incorporated to increase the power capability of large synchronous generators and had been recently found useful as part of uninterruptible power supplies, generator of both $\mathrm{dc}$ and ac electric power and stand-alone power supply. Its inherent redundancy has also been exploited to achieve better drive reliability. The split-wound synchronous machine with either round or salient-pole rotor structure has two similar but separate three-phase windings wound for the same number of poles [7].

PM motors operated as brushless dc (BLDC) drives have also received wide attention as their performance can be superior to conventional brushed dc motors and ac motors. Applications of BLDC drives with permanent-magnet excitation are increasing day by day. The use of rare earth cobalt magnets (Sm-Co) and the recently introduced neodymium-iron-boron (Nd-Fe-B) magnets can provide high torques [2]. These high magnetic field machines have good servo performance and are suitable as direct drives in robotics and automation, if appropriate modern control techniques are implemented for the control of its speed and position.

Normally a PMBLDC motor is an ac synchronous motor with permanent magnet mounted on the rotor and windings on the stator. The PM creates the rotor flux and the stator windings create electromagnetic poles. The rotor is attracted by energized stators phase generating a rotation. By using an appropriate sequence of supply to stator phases, a rotating magnetic field on the stator is created and rotor rotates. Due to the construction of brushless motor, the motor power losses are almost entirely in the stationary stator, hence heat can be easily transferred in to atmosphere.

Dual stator machines can be axial-field or radial-field machines. Compared with conventional PM machines AFPM machines normally have two air gaps. The RFPM and AFPM machines have the similar performance in terms of torque density, torque-to mass ratio, losses, and efficiency. However, the material cost of AFPM machines is much higher than that of the RFPM machines due to more magnets needed for the AFPMs. The RFPM can provide stronger cooling capability than the AFPM [8]. 
A BLDC motor can reduce the torque ripple and stator current per phase without increasing the voltage per phase and increase the reliability and power density. A high number of phases increase the torque-perampere ratio for the same machine volume [9].

\section{DUAL STATOR BRUSHLESS DC MOTOR}

It is proposed to analyze dual stator PM BLDC motor. There are two concentric stators having different diameter with one of the stator having large diameter and 36 slots in inner periphery and another stator have smaller diameter in outer periphery and 20 slots. The space between the two stators is occupied by a common cylindrical hollow rotor in which the surface mounted permanent magnets are pasted in inner and outer cylindrical surfaces of the rotor. The details of these machines are also given in Appendix.

The schematic diagram of one of the dual stator machine is shown in Fig 1.

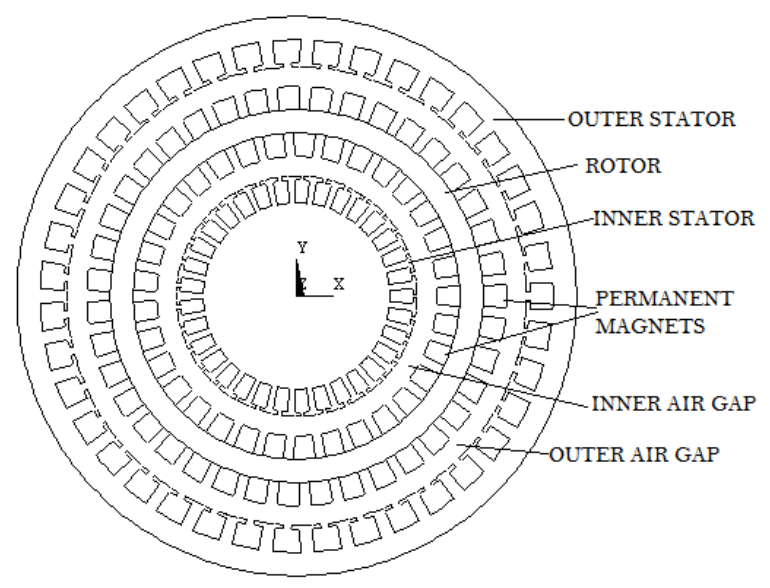

Fig 1. Schematic diagram of Dual stator PMBL DC motor

\section{Mathematical Modeling}

The PMBL DC motor can be analyzed using d-q model reported in reference [4]. When both the stators of dual stator PMBL DC motor are producing unidirectional torque, the net torque is obtained by superposition. The model of BLDC motor can be easily applied for obtaining performance characteristics of dual stator BLDC motor. It is assumed that the coils impressed voltages in different stators are having the same zero crossing as the rotational induced EMF in them. It is also assumed that switching of different coils are synchronized with the rotor position. The paper present here deals with the theoretical determination of performance characteristics of dual stator BLDC motors. For steady-state operation with balanced, sinusoidal applied stator voltages are [4],

$V_{q s}=R_{s} I_{q s}+\omega_{r} L_{d} I_{d s}+\omega_{r} \lambda_{m}$

$V_{d s}=R_{s} I_{d s}+\omega_{r} L_{d} I_{d s}+\omega_{r} \lambda_{m}$

Where, $R_{\mathrm{s}}$ is the stator resistance per phase

$\mathrm{L}_{\mathrm{s}}$ is the stator resistance per phase

$\chi_{\mathrm{m}}$ is the amplitude of flux linkages established by the permanent magnet

$\mathrm{V}_{\mathrm{qs}}$ and $\mathrm{V}_{\mathrm{ds}}$ are the stator voltages in $\mathrm{d}-\mathrm{q}$ axes frame

$\mathrm{I}_{\mathrm{qs}}$ and $\mathrm{I}_{\mathrm{ds}}$ are the stator currents in $\mathrm{d}-\mathrm{q}$ axes frame

The flux linkage $\chi_{\mathrm{m}}$ is always constant. The steady-state torque can be expressed as,

$T_{e}=\left(\frac{3}{2}\right)\left(\frac{p}{2}\right)\left[\lambda_{m} I_{q s}+\left(L_{d}-L_{q}\right) I_{q s} I_{d s}\right]$

\section{RESULTS}

The proposed dual stator PMBL DC motors reported earlier have been analyzed using the above reported model. Dual stator PMBL DC motors has been analyzed for different voltages and number of phases for different stators. The two stators of the machine are given different supply voltages as well as different phases, 


\begin{tabular}{|l|l|l|}
\hline Cases & \multicolumn{2}{|l|}{ Dual stator PMBLDC motor } \\
\hline & 20 slots & 36 slots \\
\hline \multicolumn{3}{|c|}{ Change of Voltages } \\
\hline Case A & 12volts & 24volts \\
\hline Case B & 24volts & 48volts \\
\hline Case C & 48volts & 96volts \\
\hline \multicolumn{3}{|c|}{ Change of phases } \\
\hline Case a & 1 phase & 3 phase \\
\hline Case b & 3 phase & 1 phase \\
\hline Case c & 3 phase & 3 phase \\
\hline
\end{tabular}

The torque-speed characteristics and the power-speed characteristics for the different cases of voltages are plotted,

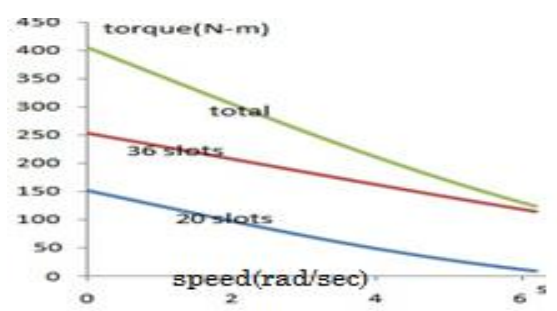

Case A $12 / 24 \mathrm{~V}$

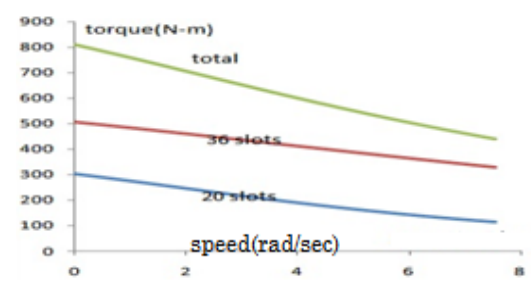

Case B $24 / 48$ V

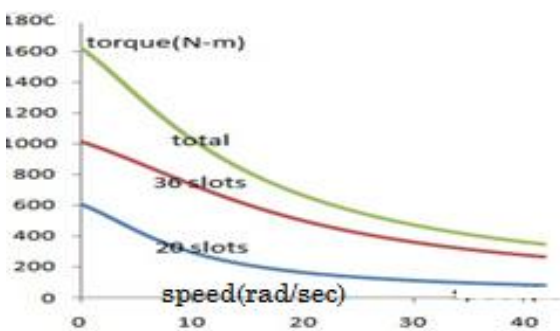

Case C $48 / 96$ V

Fig 2 Effect of changing applied voltages on torque-speed characteristics

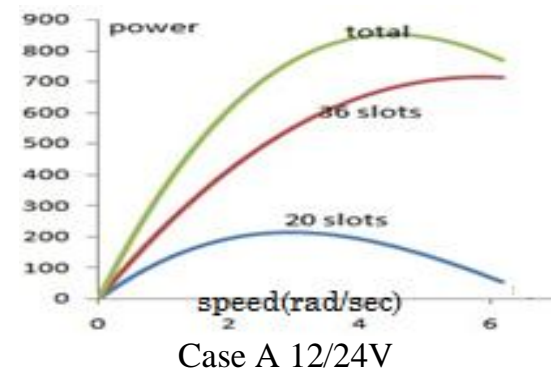




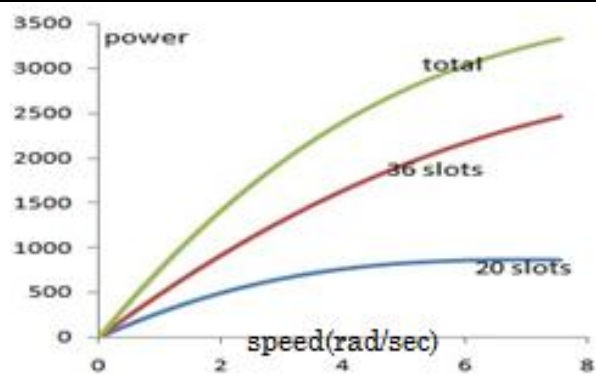

Case B 24/48 V

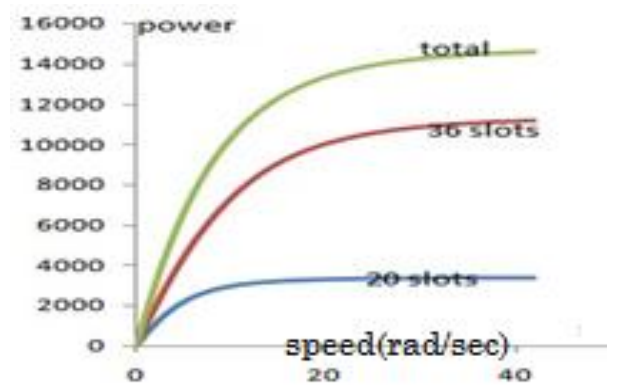

Case C $48 / 96$ V

Fig 3 Effect of changing applied voltages on power-speed characteristics

Now the dual stator machines are analyzed for different phases in stators and the torque-speed and power-speed characteristics are plotted. During the phase variation analysis in the dual stator motor the supply voltage is kept at 12 volts,

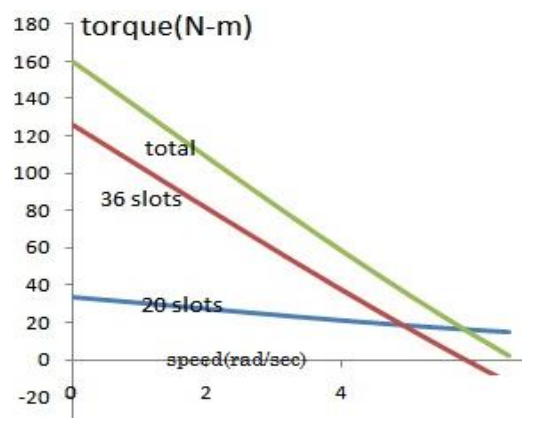

Case a Single/three phase $12 \mathrm{~V}$

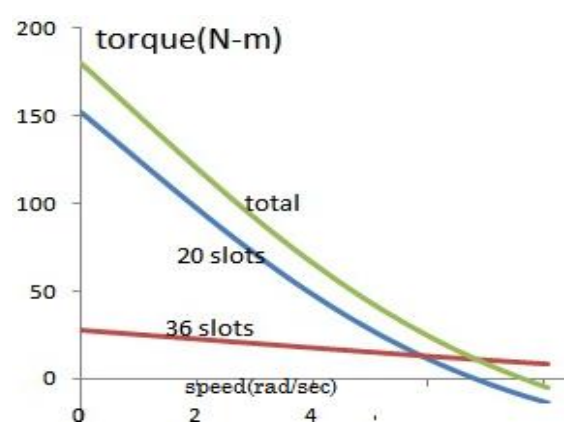

Case b Three/single phase $12 \mathrm{~V}$ 


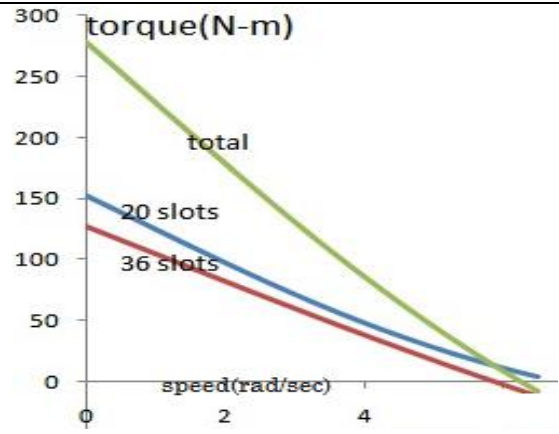

Case c Three/three phase $12 \mathrm{~V}$

Fig 4 Effect of variation of phases on torque-speed characteristics with $12 \mathrm{~V}$

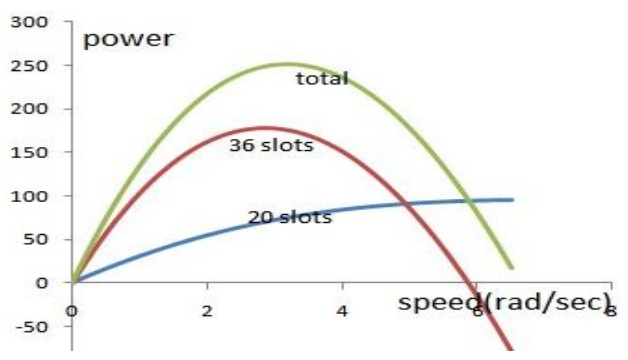

Case a Single/three phase $12 \mathrm{~V}$

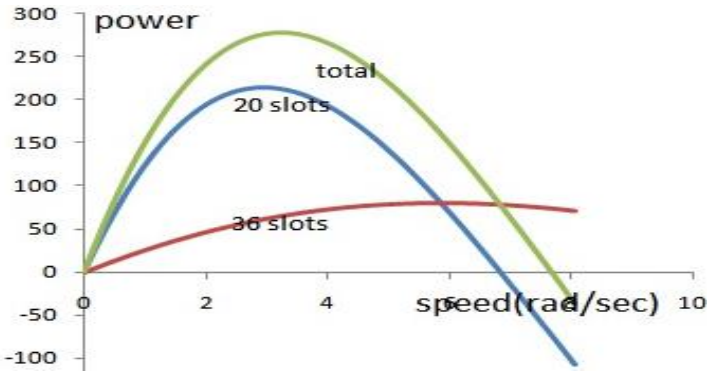

Case b Three/single phase $12 \mathrm{~V}$

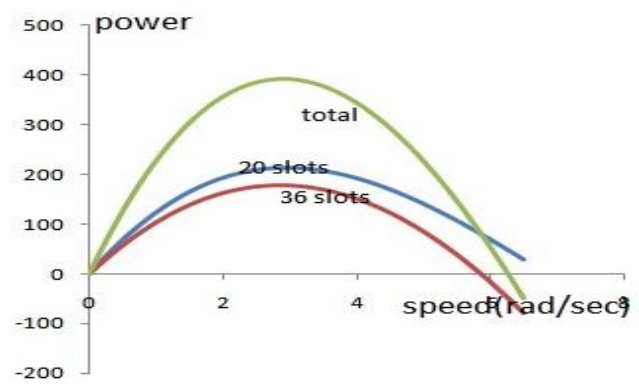

Case c Three/three phase $12 \mathrm{~V}$

Fig 5 Effect of variation of phases on power-speed characteristics with $12 \mathrm{~V}$

\section{Discussions of the Results:}

The effect of voltage variation is shown in Fig 2 (a), (b) and (c). As the voltage of any of the stator in dual stator BLDC motor increases the corresponding starting torque of the machine increases and thus the total torque increases as it is the sum of torques of both the machines. With the increase in speed, torque of the BLDC motor increases and at certain speed the torque becomes zero. For machine having different slots/poles the speed at which torque will become zero is different. For larger voltages like 96 volts, torque decreases very slowly and become almost constant. The performance like power versus speed can be easily developed. As the brushless DC motor is also known as Permanent Magnet Synchronous Motor because this power-speed 
characteristic resembles those of synchronous machine characteristics. From power-speed characteristics of Dual stator BLDC motor, it can be stated that the characteristics of this machine is stable.

Also, as the number of phases in a machine increases the starting torque also increases and in the dual stator machine with two stators having different number of phases, the stator with lower number of phase has less starting torque as compared to the machine having high number of phases. Also for different phases in different stators the torque will become zero at different speed and for the dual stator machine having same number of phases in both the stators the torque will become zero at the same speed.

From power-speed characteristics of dual stator motor having different number of phases in the two stators, the maximum power of each machine will be different and the power of different stator will reach zero at different speeds. But when the two stators of the dual stator machine have same number of phases the speed at which power will reach zero will be the same.

\section{CONCLUSIONS}

The increasing demand of power in day to day life and energy crisis have given importance to the development of dual stator PM brushless dc motor. The advantages like reliability, high power density and reduced torque-ripples are achieved. PMBLDC motor design results in low rotor inertia, higher rotor speed and higher motor supply voltage as compared to conventional dc motor. Its high reliability and robust nature also makes it suitable for electric vehicle applications. Also, permanent magnet BLDC drives are highly suitable for high-speed applications. These motors have higher power density or higher power per unit weight of motor, which makes them more attractive

\section{REFERENCES:}

[1] Djafar Hadiouche, Hubert Razik, and Abderrezak Rezzoug, "On the Modeling and Design of Dual-Stator Windings to Minimize Circulating Harmonic Currents for VSI Fed AC Machines”, IEEE Transactions on Industry Applications, Vol. 40, No. 2, pp. 506515, March-April 2004.

[2] Teck-Seng Low, Mohammed A.Jabbar, and M. Azizur Rahman, "Permanent-Magnet Motors for Brushless Operation" , IEEE Transactions on Industry Applications, Vol. 26, No.1, pp. 124-129, January/February 1990.

[3] Alfredo Mufioz-Garcia Thomas A. Lipo, "Dual Stator Winding Induction Machine Drive", IEEE Transactions 1998, pp.601-608.

[4] Paul C. Krause, Oleg Wasynczuk and Scott D.Sudhoff, "Analysis of Electric Machinery", IEEE press, IEEE power engineering society, 1994 Edition.

[5] Shuangxia Niu, K. T. Chau, Dong Zhang, J. Z. Jiang, Zheng Wang, "Design and Control of a Double-Stator Permanent-Magnet Motor Drive for Electric Vehicles", IEEE Transactions 2007, pp. 1293-1300.

[6] Xiaoyong Zhu, Dajian Chen, Li Quan, Zhiling Liao and Guohai Liu, "The Flux Controllable Permanent Magnet Brushless Machines: Concepts, Developments and Applications', IEEE Transactions 2009, IPEMC 2009, pp. 1919-1924.

[7] Zhiqiao Wu, Olorunfemi Ojo and Jyoti Sastry, "High-Performance Control of a Dual Stator Winding DC Power Induction Generator", IEEE Transactions on Industry Applications, Vol.43, No.2, pp. 582-592, March/April 2007.

[8] Ronghai Qu; Aydin, M.; Lipo, T.A., "Performance comparison of dual-rotor radial-flux and axial-flux permanent-magnet BLDC machines", IEEE Transactions 2003, Vol.3, pp. 1948-1954, June 2003.

[9] Tae-Yeong Kim; Byoung-Kuk Lee; Chung-Yuen Won, "Modeling and simulation of Multiphase BLDC motor Drive systems for autonomous underwater applications", IEEE Transactions 2007, Vol.2, pp. 1366-1371, May 2007.

\section{Appendix}

Details of Proposed Dual stator BLDC Motor:

\begin{tabular}{|c|c|c|}
\hline & $\begin{array}{c}\text { INNER } \\
\text { STATOR }\end{array}$ & $\begin{array}{c}\text { OUTER } \\
\text { STATOR }\end{array}$ \\
\hline Number of slots & 20 slots & 36 slots \\
\hline Slot/pole ratio & 1 & 1 \\
\hline $\begin{array}{c}\text { Resistance per } \\
\text { phase }\end{array}$ & $5.33 \Omega$ & $50 \mathrm{mH}$ \\
\hline $\begin{array}{c}\text { Inductance per } \\
\text { phase }\end{array}$ & $50 \mathrm{mH}$ & \\
\hline $\begin{array}{c}\text { Thickness of } \\
\text { magnet }\end{array}$ & \multicolumn{2}{|c|}{$2 \mathrm{~mm}$} \\
\hline Magnet & \multicolumn{2}{|c|}{$1 \mathrm{~mm}$} \\
\hline Air gap & \multicolumn{2}{|c|}{} \\
\hline
\end{tabular}

